\title{
Teaching Mathematics during the COVID-19 Lockdown in a Context of Historical Disadvantage
}

\author{
Brantina Chirinda *(D), Mdutshekelwa Ndlovu and Erica Spangenberg
}

Department of Science and Technology Education, P.O. Box 524, University of Johannesburg, 2006 Johannesburg, South Africa; mndlovu@uj.ac.za (M.N.); ericas@uj.ac.za (E.S.)

* Correspondence: brantinac@yahoo.com or brantinac@uj.ac.za

Citation: Chirinda, B.; Ndlovu, M.; Spangenberg, E. Teaching

Mathematics during the COVID-19 Lockdown in a Context of Historical Disadvantage. Educ. Sci. 2021, 11, 177 https://doi.org/10.3390/

educsci11040177

Academic Editor: James Albright

Received: 25 January 2021

Accepted: 5 March 2021

Published: 8 April 2021

Publisher's Note: MDPI stays neutral with regard to jurisdictional claims in published maps and institutional affiliations.

Copyright: (C) 2021 by the authors. Licensee MDPI, Basel, Switzerland. This article is an open access article distributed under the terms and conditions of the Creative Commons Attribution (CC BY) license (https:// creativecommons.org/licenses/by/ $4.0 /)$.

\begin{abstract}
The COVID-19 global pandemic widely affected education across the world and engendered unprecedented scenarios that required expeditious responses. In South Africa, the pandemic came on top of pre-existing inequalities in the education system. Using a qualitative research method of exploratory and descriptive nature, this study engaged a social justice framework to explore the teaching and learning of mathematics during the COVID-19 lockdown in a context of historical disadvantage. A sample of twenty-three Grade 12 mathematics teachers at various public secondary schools in Gauteng, South Africa was used in the study. The teachers were selected through purposive sampling. A Google-generated open-ended questionnaire and follow-up telephonic interviews were used to collect data. Data were analysed thematically in five steps. The findings revealed that the WhatsApp platform is a valuable tool that can support the teaching and learning of mathematics beyond the classroom in the contexts of historical disadvantage. The findings also provided insights into how mathematics teachers became learners themselves during emergency remote teaching (ERT) as they had to adapt to digital teaching, find solutions to unfamiliar problems and acquire knowledge from a larger mathematics education community around the globe. The article discusses these findings and teachers' challenges of transitioning from traditional face-to-face classrooms to ERT and how they were addressed. At the time of publishing the article, most learners in South Africa had started going to school on a rotational basis. Nonetheless, the study reported in this article is of importance as ERT in the context of historical disadvantage has foregrounded issues of inequality in the South African education system that must be dealt with urgently.
\end{abstract}

Keywords: COVID-19 pandemic; inequality; emergency remote teaching; lockdown; mathematics education; mathematics teachers; social justice; WhatsApp platform

\section{Introduction}

The COVID-19 outbreak was first identified in Wuhan, China in December 2019. The outbreak was declared a Public Health Emergency of International Concern on the 10th of January 2020, and a global pandemic on the 11th of March 2020 by the World Health Organization [1]. This declaration was followed by schools and universities closing in most parts of the world, precipitating the sudden need for remote learning. Worldwide, more than 1.5 billion learners, which is $90 \%$ of the world's registered learners, were left without education due to the COVID-19 pandemic [2]. South Africa recorded its first COVID-19 case on the 5th of March 2020 and began its nationwide lockdown on the 27th of March 2020 to mitigate the spread of the virus. The decision by the government to lock down the country forced the Department of Basic Education to close all schools, forcing school authorities to move from traditional face-to-face instruction to online learning environments $[3,4]$. Under the protracted lockdowns, many governments around the world began to experiment with emergency remote teaching (ERT) to cope with the COVID-19 pandemic [5]. Accordingly, the South African government insisted on "rescuing the school year" and encouraged teachers to perform some form of ERT. The COVID-19 pandemic was a new event, and 
most teachers at public schools had not performed online teaching prior to the pandemic. Teachers had to "jump in at the deep end" without resources, knowledge, or support [4] (p. 823). In this regard, this article explores how Grade 12 mathematics teachers at South African public secondary schools responded to the call for ERT due to the COVID-19 pandemic.

The study was done during the period when face-to-face learning around the world had come to a standstill due to the COVID-19 lockdown. At the time of publishing the article, most learners in South Africa had started going to school on a rotational basis. For all learners to be taught by their teachers at school, while still maintaining social distance, they were now following a normal one-week or two-week cycle whereby each class was split into two groups, Group A and B. Group A would do face-to face classes on days when Group B would stay at home and receive information on the most available WhatsApp social media platform on alternate days and vice versa. Learner attendance cycles depended on each school's circumstances. The study reported in this article is of importance as ERT in the context of historical disadvantage has foregrounded issues of inequality in the South African education. Issues of inequality in South Africa are not new; nonetheless, the COVID-19 pandemic has laid bare these realities of educational inequality from a totally different perspective which must be dealt with urgently.

\subsection{The Purpose of the Study}

The main purpose of the study was to explore how Grade 12 mathematics teachers at South African public secondary schools responded to the call for ERT due to the COVID-19 pandemic. This study looked at Grade 12 teachers because they are the ones who were forced to adopt ERT during the lockdown since their learners were required to write schoolleaving exams at the end of the year. The study focused on teachers at public secondary schools (quintile 1, 2, and 3 schools) because challenges linked to online learning are more profound in historically under-resourced schools.

\subsection{Research Question}

The study was guided by the following research question:

- How did mathematics teachers at South African public secondary schools respond to the call for ERT during the COVID-19 lockdown scenario in a context of historical disadvantage?

\subsection{Understanding Emergency Remote Teaching during the COVID-19 Lockdown}

ERT is a non-permanent shift in teaching under an anticipated circumstance and is quite different from online teaching and learning which has existed for years [6]. ERT is a temporary solution to a sudden crisis, yet online teaching and learning are permanent. Hodges et al. explain that ERT "involves the use of fully remote teaching solutions for instruction or education that would otherwise have been delivered face-to-face or as blended or hybrid courses and that will, hopefully, return to the original format once the crisis or emergency has abated. The primary objective in these circumstances is not to re-create a robust educational ecosystem but rather to provide temporary access to instruction and instructional support in a manner that is quick to set up and is reliably available during an emergency or crisis" (Emergency Remote Teaching section, para. 1).

The distinction between ERT and online teaching and learning is important because creating learning approaches or methods under incorrect assumptions and conjectures usually leads to misconceptions and errors in an education system. ERT can be either asynchronous or synchronous. Asynchronous learning is when learners have options to participate in learning during their chosen times. Participation is via digital tools such as the WhatsApp platform or discussion boards for asynchronous learning. Synchronous learning happens through live video or live chats with instant feedback [7].

The COVID-19 disruptions were unplanned such that ERT was implemented by many institutions from around the world as a temporary solution to teaching. Disruptions to 
education are not new because crises have existed for as long as we can remember in several parts of the world. In such times, countries have implemented ERT and learning through various channels. Afghanistan adopted radio and DVDs to disseminate education when schools were closed due to the conflict in the country [8]. The Syrian conflict has stretched for a long time and education technology (EdTech) was developed to provide some form of learning during the conflict [9]. Recently, due to the COVID-19 pandemic, ERT was adopted to teach mathematics at several institutions in several countries, including South Africa [10-13]. Aldon et al. [10] explored how mathematics teachers from France, Israel, Italy and Germany managed the teaching and learning of mathematics during the COVID19 lockdown. They found that the unprecedented situation led teachers to adapt their teaching and to change their praxeologies. Drijvers [11] investigated distance mathematics teaching in Belgium, Germany and the Netherlands during the COVID-19 lockdown. The findings were that teachers' engagement in distance teaching may have caused them to forget the mathematics tools and mathematics didactic approaches. Drijvers [11] recommends that mathematics teachers should adopt rich, didactic and interactive distance teaching practices. Mailizar et al. [12] investigated Indonesian secondary mathematics teachers' views on e-learning implementation during the COVID-19 pandemic. They found that the teachers experienced challenges in implementing digital teaching during school closures. The challenges included Indonesian learners' lack of access to devices and internet connection and limited knowledge and skills in e-learning use. Naidoo [13] looked into South African postgraduate mathematics education students' experiences with digital platforms for learning during the COVID-19 pandemic. Their findings were that digital platforms provide unlimited access to module material and resources. However, the students stated that the digital resources were expensive, and they needed training to use the digital platforms effectively.

Disruption of education in South Africa is not new either. Between 2015 and 2017, South African universities were disrupted by the \#FeesMustFall demonstrations by students. The \#FeesMustFall disturbances were equated to the COVID-19 current disruptions by [14], who contended that the same fissures and inequalities in teaching and learning in South Africa are as visible now as they were then. The next section discusses the inequalities that existed in South Africa before the COVID-19 pandemic.

\subsection{The South African Pre-COVID-19 Pandemic Context}

In this section, the South African pre-COVID-19 context is delineated to illustrate the inequalities that pre-existed which [15] (p. 45) named "societal comorbidities". South African public schools are categorized into five groups, called quintiles, with quintile 1 schools being the "poorest" and usually based in under-served communities where resources are limited, while the quintile 5 schools are the "least poor", or wealthiest, and often well resourced. Quintile 1, 2 and 3 schools are non-fee paying and primarily located in townships, informal settlements or rural areas. Township schools were and are still situated on the peripherals of major cities and were formed essentially to segregate non-whites from whites during the apartheid era. Apartheid is a former South African policy of separate (racial) development that was created by the then National Party to economically and politically subjugate the non-white population. Apartheid created huge inequalities such that after 1994 (post-apartheid), the poorest Black people resorted to staying in informal settlements since they could not afford to pay for rent, electricity and other basic services. Quintiles 4 and 5 are predominantly former model $C$ state schools and independent schools. Generally, the basic education received by learners in quintile 4 and 5 schools is better than that at non-fee-paying public schools in townships or informal settlements. Independent schools are not part of the government-run school system and are usually found in the more affluent suburbs of South Africa. Former model C schools are semi-private institutions which were more generously funded whites-only government schools during the apartheid era. They are now multicultural, significantly diverse, receive government funding for some staff salaries and parents are charged fees. These former 
model C schools are predominantly located in affluent suburbs of South Africa and because of the Groups Areas Act of 1950, only Whites had access to them. With the Groups Areas Act of 1950, learners only had access to schools in the area they lived in. Unfortunately, that legacy largely persists today. Classes at quintile 4 and 5 schools commonly have fewer than 30 learners as compared to the characteristically more than 50 learners per class at government-run quintile 1-3 public schools.

School clustering was done in South Africa to address past inequities and to guarantee an equal and fair distribution of resources across schools. Nonetheless, these past inequities did not just disappear overnight such that South Africa remains one of the most unequal societies in the world [16]. This means that South African learners entered the COVID-19 lockdown period in unequal economic circumstances with major differences still existing regarding learners' access to information technology resources. Public schools in South Africa have some form of information technology resources sufficient for less than 50\% of the learners in each class having a computer with internet access [17]. Learners in under-served communities do not have access to digital resources at home necessary for online learning. Given the access to digital resources, the projection was that less than $10 \%$ of South African learners would manage to continue learning at home during the COVID-19 lockdown [17]. In this regard, social justice theory was relevant in framing the study. Social justice education aims for "full and equal participation of all groups in society that is mutually shaped to meet their needs" [18] (p. 3).

Pre-COVID-19 pandemic, South African teachers at public schools predominantly conducted face-to-face instruction. Teachers and learners met on every learning day and explored mathematics. Participant teachers had not received substantive professional development to support blended teaching and learning or to fully apply online teaching and learning. Without prior experience, ERT compelled teachers to adjust to online teaching to guarantee a continuation in mathematics learning despite the obstacles that emerged from the lockdown due to the COVID-19 pandemic.

\section{Materials and Methods}

A qualitative research method of exploratory and descriptive nature was adopted for the study. The qualitative research was appropriate because it derives meaning from the research participants' perspective [19]. The study was exploratory because an inquiry into a new topic on the COVID-19 pandemic was conducted to acquire a new understanding of the phenomenon [20]. To gain a deeper and wider understanding of the teaching of mathematics during the novel COVID-19 pandemic, a descriptive design was adopted. The descriptive design permitted researchers to gain a detailed account of experiences from teachers and to give a detailed description of the context of the study [21].

Sixty Grade 12 mathematics teachers at various public secondary schools in Gauteng, South Africa were invited to participate in the study via e-mails and WhatsApp messages. A total of 32 teachers consented to participate and eventually, while 23 responded to the Google-generated open-ended questionnaire. Follow-up telephonic interviews were conducted with seven teachers. All the teachers were working full time at the public schools. Fourteen teachers held a Bachelor's education degree in mathematics education, five had Honors degrees in mathematics education and four had a Master's degree in mathematics education. This indicates that the teachers who participated in this study had adequate qualifications that are required to teach secondary school mathematics in South Africa. Teachers' experience of teaching mathematics was evenly distributed and ranged between 2 and 20 years. Of the participants, 12 were women (52\%) and 11 were men $(48 \%)$, representing a gender balance of participants. Teachers were purposively selected because they were teaching Grade 12 learners at public secondary schools in townships and informal settlements, could be conveniently accessed by the researchers and were available to participate in the study. Grade 12 mathematics teachers were chosen to participate in the study because they had WhatsApp groups of their classes in place before lockdown due to the COVID-19 pandemic. Teachers usually create Grade 12 WhatsApp groups at 
the beginning of each year so that they can have regular communication with the learners who will be writing school-leaving exams at the end of the year. The research team, who worked at a South African university, consisted of two women and one man. Prior to the study, two of the researchers had been doing research for over twenty years and were well-experienced in designing data collection instruments.

A Google-generated open-ended questionnaire and telephonic interviews were used for data collection. Two data sources were used for data triangulation to develop a comprehensive understanding of the phenomena. South Africa as a country entered lockdown on the 27th of March 2020, and researchers started to design the questionnaire on the 1st of April 2020. The questionnaire was fully developed by the 28th of April 2020, and researchers immediately started seeking ethical clearance from the overseeing university, Department of Basic Education, and the Grade 12 mathematics teachers. Initially, the researchers e-mailed participant teachers an informed consent form stating the objectives and process of the study. The informed consent form clearly stated that the participants could leave the study at any time without prejudice. After reading and understanding the informed consent form, participants signed as a way of accepting to participate in the study voluntarily. Teachers were required to send back the forms through e-mail or a WhatsApp message to the first author, indicating whether they consented to participate in the study or not. Pseudonyms were assigned to participants to enforce their privacy, anonymity and confidentiality. Ethical clearance was obtained from the overseeing university and the Department of Basic Education. After ethical clearance, the questionnaire was opened for teachers to answer online on the 18th of May 2020.

The questionnaire was closed on the 31st of May 2020 because the Minister of Basic Education had signaled that South African schools would partially open for Grade 12 learners in the month of June 2020. The questionnaire elicited information pertaining to demographic characteristics that included teachers' age, gender, qualifications, and teaching experience. The following were some of the questionnaire items: What were your teaching practices before lockdown? What were your teaching practices during the lockdown? Did you attempt to teach synchronously? If so, how did you do it? Did you try to carry out assessments? If so, how did you do it? What sources did you draw the content you were teaching from during ERT? How do you feel about ERT? If you experience ERT again what would you do differently? What were the challenges you experienced during ERT? What do you feel you have achieved with ERT during the COVID-19 lockdown? Any further comments?

The questionnaire was pilot tested before the data collection process. Four Grade 12 teachers at public secondary schools, who were non-participants of the main study, participated in the pilot study. Pilot testing helped the researchers to establish the practicability, suitability and appropriateness of the items of the questionnaire and as a result to enhance the dependability of the findings.

Follow-up semistructured telephonic interviews were conducted with seven teachers whose responses were not clear on the questionnaire. Some of these teachers had not made clear on their responses when, how and why they had implemented some teaching practices. The follow-up semistructured telephonic interview questions included: Please take me through the timeline of when this happened? You have indicated that you designed your own whiteboard/blackboard; please describe further how you did this? You noted that you had WhatsApp groups of Grade 12 learners that were in existence before the COVID-19 lockdown; please explain further. You indicated that you drew information from around the globe; please clarify.

\section{Data Analysis}

The telephonic interviews were transcribed and analyzed thematically together with the teachers' responses on the Google-generated open-ended questionnaire [22]. The data analysis was categorized into five steps. The researchers started by browsing through all the transcripts to get a first impression. After noting down the initial impression, they 
read the transcripts one by one to ensure acquaintance with the data. In the second step, the researchers conducted open coding by labeling relevant words, phrases and sentences on the transcripts. In the third step, the researchers inspected the codes, in some cases combining two or more codes to create new codes, and discarded the codes that they felt were unimportant. While keeping an unbiased, open mind, the researchers decided on the important codes and classified them into themes. In the fourth step, the researchers inspected the emerging themes and decided on the most relevant and abandoned the ones that they felt were irrelevant. In the final step, the researchers scrutinized the selected themes, identifying the connections among them and deciding if a hierarchy existed among them or if one theme was more important than others. In the end, the following three themes were selected which the researchers felt answered the research question: mathematics teachers as learners, adoption of the WhatsApp platform as an online interactive tool and the need for mathematics teachers to learn from a larger mathematics education community around the globe.

To improve the dependability of the data analysis process, an independent coder analyzed the questionnaire responses and the transcripts from the follow-up telephonic interviews using the same data analysis process that was used by the researchers. The independent coder was provided with the questionnaire, a description of the followup interviews and a description of the data analysis process. The independent coder independently coded the responses and compared the emerging themes with those of the researchers. The independent coder identified four themes, but the researchers had identified only three, with two themes common to both analyses. Consequently, the researchers evaluated the data analysis process to come up with sufficient details and coherence to assist the independent coder. After this, a second round of independent data analyses was performed by the researchers and the independent coder. In this round, the independent coder merged two themes and remained with three themes similar to those of the researchers. The two themes that were merged by the independent coder were collaborating with mathematics teachers beyond borders and the importance of mathematics teachers to replicate resources. They were merged into one theme: the need of mathematics teachers to learn from a larger mathematics education community around the globe. After this, the researchers and independent coder reached a consensus on how to name the emerged themes [23]. Themes were verified by participants, thereby undertaking the process of member-checking. This process of improving dependability implies that the data collection and analysis processes could be used by any researcher looking at the teaching of mathematics during the COVID-19 pandemic to replicate the results of the study. Next, the article discusses the themes which are supported by various excerpts from the teachers, presented in italics below.

\section{Results}

This study explored the teaching of mathematics during the COVID-19 lockdown in a context of historical disadvantage. In the next sections, the themes that emerged from the data analysis are presented.

\subsection{Mathematics Teachers as Learners during ERT}

The COVID-19 pandemic is an unprecedented challenge to societies around the world, and mathematics teachers in South Africa had to become learners themselves as they learned to support their learners through unexplored teaching methods and had to adapt to digital teaching for the first time. Teachers indicated that once the government signaled the need for ERT, they began to try various video communication tools such as Zoom (video-telephony and online chat), YouTube (online video-sharing platform) and Facebook Live. Teachers indicated that they researched information on digital learning platforms such as Google Classroom, Blackboard Collaborate, WhatsApp and flipped classrooms. From their responses on the questionnaire, teachers had never used these tools in their 
teaching of mathematics and had to quickly think about how they could integrate them into their teaching.

Several teachers learned how to create "whiteboards" by pasting pieces of paper on the walls of their homes. Teachers taught from these "whiteboards", at the same time videorecording themselves on their phones as described by teacher Harry: "I had to improvise. I pasted pieces of paper on the walls of my bedroom and used them like a whiteboard. I chose my bedroom so that I could teach quietly and take clear videos of myself without my kids disturbing me. I shared the videos with learners and parents on the groups that I had created on the WhatsApp platform." Teachers shared the recorded videos; however, as indicated in the next section, learners and parents read the messages but did not have sufficient data to download the videos.

Before the COVID-19 pandemic, teachers had not used radio and television (TV) to supplement learning. During the pandemic, teachers realized most households in South Africa have access to radio and TV and integrated them into ERT as indicated by teacher Abel: "As technology has advanced in the recent years, with most learners having smartphones, we were no longer using radio and TV as a medium of learning. Nevertheless, most learners have TV or radio at home such that I now require learners to follow some schooling programs on TV or radio as I now included them in my ERT. Some programs are even from the Department of Basic Education." Teachers had to learn how to merge "COVID-19 Learner Support" schooling programs on TV and radio with their ERT. The "COVID-19 Learner Support" was the Department of Basic Education (DBE)'s partnership with the South African Broadcasting Corporation (SABC) to provide some form of learning to Grades 10 to 12 on TV and radio [24]. Use of TV and radio as a medium of learning in the time of crisis is not new as they have been frequently used in the past in the time of violence and conflict [8].

Teachers indicated that they had to learn to be innovative. They learnt to organize timed discussion sessions on the WhatsApp platform so that learners could interact with their classmates. Teachers learnt to be competent in choosing problems that would encourage learner engagement with each other during the timed discussion sessions. At the beginning of the lockdown, a few teachers indicated that they narrated PowerPoint slides and shared them to the WhatsApp groups. This strategy was quickly abandoned as teachers realized that most learners did not have sufficient data to download the narrated PowerPoint slides as noted by teacher Abedi: "Initially, I came up with an idea of narrating PowerPoint slides and loaded the slides on both the parents' and learners' WhatsApp groups. I quickly realized that most parents and learners did not have sufficient data to download these slides and I quickly abandoned the technique."

\subsection{Pedagogical Practices for ERT: Adoption of the WhatsApp Platform as an Online Interactive Tool}

Zoom, YouTube, Facebook Live and WhatsApp messaging were the top online platforms that were available for South African mathematics teachers to deliver lessons in the context of the study. With Zoom, teachers can teach learners in an online class and can create break-out rooms; however, the findings were that in the context of study, learners did not have enough data to attend online lessons. Teachers can create mini lessons on YouTube; however, teachers indicated that in the context, learners did not have enough data and appropriate connectivity to watch the videos. Facebook Live is user-friendly, does not require any special skills or settings and is a suitable online learning method because most teachers and learners have Facebook accounts. Nonetheless, teachers could not use Facebook Live for ERT because most learners did not have sufficient data to attend the live lessons. As a result, teachers used the WhatsApp platform to keep the learning process going and to stay in contact with learners during the COVID-19 lockdown.

WhatsApp is a free messenger application that works across various platforms. It is used by individuals to send text messages and multimedia messages such as photos, videos and audio-recordings. This means that most, if not all learners were remarkably familiar with the technology. Therefore, it was easier for teachers to use the platform to perform some kind of teaching mathematics synchronously or asynchronously. 
Teachers indicated that they created videos, audio lessons and PDF documents with problems or assignments and sent them directly to the learners on the WhatsApp platform. With the platform, there are usually no technical issues; however, most learners did not have sufficient data to download the videos and PDF documents. Teachers noted that learners opened the WhatsApp messages but did not have sufficient data to download the resources. This led teachers to use text messages to provide questions, answers and clarification on working through mathematical contentas noted by teacher Sally: "Rather than sending videos and Pdf documents I now send text messages that I know learners read. I also send them tips for self-study, for setting goals and aspirations, and for handling their circumstances at home." From teacher Sally's quote, it can be noted that teachers also used text messages to send advice to learners for self-study and how to cope with working from home.

Further findings were that most teachers used the WhatsApp Group Chats feature to create learning and study groups. Teachers also created WhatsApp groups for parents where they disseminated learning materials in the form of pictures of book pages, worksheets, short videos, etc. Nevertheless, teachers discovered that many parents did not have data to download the materials. Teachers could not print the learning materials for parents to collect from school because this was during the hard lockdown where no movement was allowed. This was noted by teacher Nico: "I have discovered that many parents open the WhatsApp messages that I send with pictures of book pages but do not have data to download them. I guess once lockdown rules have been eased, I can start printing the materials at school and ask parents to collect them. I will try to explain to parents how to use the materials so that they can help learners at home." In some schools, teachers proposed sharing learning material through flash disks once lockdown rules were eased, but most parents and learners did not have the necessary devices such as desktops or laptops to work through the learning material as observed by teacher Clara: "Since parents and learners do not have sufficient data to download materials that we send on WhatsApp, we proposed to share material on flash disks. But the problem is that parents cannot afford desktops or laptops for learners to study material on the flash disks." Since learners are easily distracted at home, teachers pointed out that they also used the platform to send parents tips on how to create a structured environment at home conducive to learning.

Some teachers mentioned that they had wanted to conduct one-on-one consultations using WhatsApp video calls, but this was impossible because most learners could not afford data to participate in the video calls. This is revealed in the following excerpt by teacher John: "There are some learners that require me as the teacher to conduct one-on-one explanations, but they cannot afford data for video calls. However, in former model C schools, teachers are doing online teaching and one-on-one video consultations." Teacher John's comment highlights the variations in affordability, income and access to resources that exist in South African society since former model C schools and independent schools smoothly moved into online learning without many obstacles.

Some teachers scheduled an hour where it was mandatory for all learners of a particular grade to be active on the WhatsApp platform. This was an attempt by teachers to create synchronous sessions where learners solved mathematical problems and asked questions while interacting with their peers online. Teachers indicated that it was difficult for them to know if this synchronous process worked, since they did not know if learners were genuinely working as reflected by teacher Catherine: "This was a good move, but I am not sure if it was successful. I would see some learners online, but I was not sure if they were doing schoolwork." Teacher Andrew noted that at one point, he required learners to prove the first theorem of circle geometry which states that the angle at the center of a circle is twice the angle at the circumference. This proof is expected to be easy for Grade 12 leaners to prove, but teacher Andrew reflected that almost half of the learners could not complete the proof in half an hour. This probably suggests that learners were not focusing on their work during the synchronous sessions.

The teachers observed that using the WhatsApp platform was challenging as most learners could not understand course expectations and struggled to stay motivated because 
of the lack of in-person interaction. As noted by teacher Catherine: "Sometimes learners sound demotivated during the WhatsApp discussions. WhatsApp communication can never be compared to classroom contact time which should continue to exist as the backbone of learning." Teacher Catherine's observation seems to indicate that online interaction can hardly replace the importance of physical teaching.

Teachers indicated that they felt exhausted from being continuously online using the WhatsApp platform, as noted by teacher James: "I find it a challenge to keep on interacting continuously online with learners and parents. Sometimes learners send messages late at a night." Accordingly, teachers indicated that they ended up requiring learners to set up their WhatsApp chat groups so that they could give peer assistance to one another. This was indicated by teacher Robert: "We now require learners to set up their WhatsApp chat groups so that they can help one another as peers. This takes the pressure off me."

A few teachers in the study indicated that they struggled to get adequate data for internet connection as they did not have Wi-Fi facilities at home.

\subsection{The Need for Mathematics Teachers to Learn from a Larger Mathematics Education Community from around the Globe}

This study explored how mathematics teachers at South African public secondary schools navigated from face-to-face instruction to ERT due to the COVID-19 pandemic. Teachers' responses on the questionnaire and to the telephonic interviews indicated that the speed with which they had to implement ERT in their practices was unprecedented. This meant that teachers had to find information or seek guidance from around the globe on how to implement ERT. Teachers indicated that they found the value of learning from a larger mathematics education community which included their school colleagues, South African teachers, and international teachers. Teachers engaged with the larger mathematics education community to understand how the COVID-19 pandemic was impacting different schools in different contexts and to learn how mathematics teachers were adjusting to rapid changes.

Teachers acknowledged that they took advantage of the online platforms to get new ideas and methods to deliver mathematical content during ERT as noted by teacher Stella: "I had to go online and befriend some year 12 maths teachers in Australia on Facebook. This was so that I could learn how they were conducting virtual mathematics lessons during ERT. I was lucky that these teachers were free to share their lesson plans, teaching videos, and several maths content resources."

Many teachers indicated that they joined international mathematics discussion groups on social media (WhatsApp, Facebook, Twitter and Instagram) that focused on implementing digital platforms in the mathematics classroom as disclosed by teacher Michael: "I had to join a Facebook group from Israel that focused on how to implement technology in an online environment when teaching Euclidean geometry and Analytical geometry. The group helped me a lot since I got ideas on how to design various learning activities on circle geometry that I implemented on the WhatsApp platform." Teachers revealed that learning from the international community provided fresh ideas as most local teachers were only offering learners mathematics worksheets to complete as indicated by teacher Stella: "I get innovative ideas to implement in my ERT from the teachers on the Australian group. This is helpful as compared to our local maths teacher groups were we share worksheets only."

\section{Discussion}

The themes identified in this study address how Grade 12 mathematics teachers at South African public secondary schools responded to the call for ERT during the COVID-19 lockdown scenario in a context of historical disadvantage. The pandemic was unprecedented in how all levels of South African educational institutions had to immediately stop face-to-face interaction and speedily adapt to ERT and learning. Mathematics teachers at public schools encountered the digital environment for the first time and resorted to finding information and seeking guidance from other teachers around the world. Teachers reflected that they found value in acquiring knowledge on how to implement ERT from 
the larger mathematics education community. Teachers became learners themselves as they had to adapt to digital teaching and extemporize quick solutions in less-than-ideal conditions. Teachers had to think innovatively and find solutions to unfamiliar problems that were emerging from the digital environment which they were experiencing for the first time. This is in tune with Aldon et al.'s [10] findings from their study of teaching-learning practices in the context of the COVID-19 lockdown of 700 teachers from four different countries. Aldon et al. [10] underlined that although the pandemic shocked teachers, it inspired them to be innovative.

This study found that teachers and learners at schools in contexts of historical disadvantage were unable to shift smoothly to online teaching and learning because of insufficient digital resources such as smartphones, data, Wi-Fi and internet connectivity. However, South African learners at privileged schools effortlessly transitioned from face-toface learning to online learning through Zoom, Teams, Google Classroom, etc. [15,25]. This finding shows that the COVID-19 pandemic foregrounded issues of historical inequality in the South African education system which have existed for a long time. Given the situation, the WhatsApp platform was a valuable interactive tool in the continuation of education in contexts of disadvantage; nonetheless, some learners did not have smartphones but only had feature phones. The case of learners having only feature phones illustrates that the issue of access does not only mean access to devices but encompasses "adequacy and quality" [14] (p. 954). Learners who had smartphones could not afford the data. Many disadvantaged families could not download educational material during ERT because of data costs [25]. This was not unexpected because South Africa is one of the countries in Africa with the most expensive data for mobile phones [16]. This finding corroborates [26] and Naidoo's [13] findings that devices, data and resources for online learning are expensive. Unless data costs decrease in South Africa, the gap in education access and, thus, the vast gap between the rich and poor will worsen. The issue of data costs, lack of adequate devices and connectivity corresponds with the findings of a study done in Ghana, which is also a developing country like South Africa [27].

Learners taught by participant teachers could not even attend live lessons on Teams, Zoom or Facebook Live, meaning that they could not fully engage with the mathematical content. Participating in live lessons could have given learners opportunities to participate in discussions, ask questions and clarify misconceptions or misunderstandings. If learners had afforded data for the Zoom facility, teachers would have created smaller breakout groups during live sessions so that learners had the opportunity to support each other and be comfortable to ask questions in smaller groups. This demonstrates that educational inequalities in South Africa are "remarkably persistent" [16] since learners in privileged schools could attend live lessons on Teams, Zoom or Facebook Live.

Since many learners in the context of the study could not access learning materials that were made available on the WhatsApp platform, it meant that "the poorest and most vulnerable members of society are being hardest hit, both by the pandemic and the response" [28] (p. 1). The findings in the study seem to suggest that the COVID-19 pandemic has perpetuated educational inequalities in South Africa, since former model $\mathrm{C}$ and private schools adopted ERT without facing these challenges. This finding is in corroboration with UNESCO's observations that the closing down of schools during the COVID-19 pandemic has deepened learning inequalities and has disadvantaged vulnerable learners and those who require extra assistance in their learning. The long-established structural inequalities in South Africa between the rich and the poor were made visible by the COVID-19 pandemic. The pandemic has "made visible, the invisible, or ignored manifestations and mechanisms of inequality" [14] (p. 949); amplified inequalities in education [15]; and allowed us to notice all the dysfunctional areas [29]. This implies that the social exclusion and social divides that existed before the COVID-19 pandemic are now noticeable.

The findings revealed that the WhatsApp platform was a valuable tool for teachers since it offered flexibility in the teaching time. Teachers adjusted their practice under an 
unprecedented situation and were constantly available on the WhatsApp platform, which made the platform a convenient tool for teaching and learning of mathematics during the pandemic. Nevertheless, the use of the WhatsApp platform had its limitations as teachers described extreme fatigue from interacting continuously with parents and learners on the platform. Some teachers did not have Wi-Fi at home and as a result could not afford sufficient data to continuously stay online. This finding falls in the category of inequality once more since most teachers at privileged schools continued with online learning seamlessly. This means that the government must provide teachers in contexts of historical disadvantage with adequate data for internet connectivity so that they can conduct online teaching without facing any obstacles.

Teachers were worried that some learners were online but not focusing on schoolwork. Teachers noted that during the hour set for discussions, learners were distracted since they failed to manage their time efficiently. Most teachers reflected that most learners could not complete given problems during the set time. This was not surprising because most learners are not motivated to learn in the absence of a teacher or a structured learning environment [30]. It is also common that when learners are learning from home, family responsibilities need to be completed first before participating in schoolwork [13]. It is also natural that learners get distracted when they have family and older or younger siblings around. Distractions at home happen to all learners, even to those whose homes are conducive, structured and supportive [25]. This led teachers to be unsure if the work their learners covered on the WhatsApp platform at home was adequate. These findings imply that the true impact of the WhatsApp platform on mathematics learning during the COVID-19 lockdown is unknown.

Teachers noted that some learners were not motivated to learn during ERT because of lack of in-person interaction. This is expected because "we are social people and we need company" [4] (p. 822). Naturally, physical interaction encourages and nurtures learners' social skills. Learners will miss the social interaction that occurs in classrooms if the COVID-19 pandemic persists and online learning continues.

\section{Looking Ahead}

This study was done to answer the research question: How did mathematics teachers at South African public secondary schools respond to the call for ERT during the COVID-19 lockdown scenario in a context of historical disadvantage? The study displayed that the impact of the COVID-19 pandemic, which was aggravated by learners' inability to access resources, reflects historic inequalities in the South African education system. Aspects of inequality and social exclusion surfaced incessantly during the study. Nevertheless, this is a golden moment to capitalize on the COVID-19 pandemic by noticing all equality gaps that are emerging and trying to close them. It is important to remind ourselves of the digital divide which will be definitely exacerbated if educational access is determined by access to digital resources. In recent years, educational systems in several countries including the South African education system have concentrated on digital transformation in the fourth industrial revolution (4IR) such that it was expected that the COVID-19 pandemic would push most education systems into full online education. This did not happen in South Africa as the state of affairs for such a form of education was unavailable in underserviced areas of South Africa. This was brought to light by teachers' reflections on their experiences and learners' access to resources. The COVID-19 pandemic did not only have policy implications but has offered routes to reshape policy frameworks concerning digital transformation in education. For digital transformation to occur in education, digital resources must be freely available to all learners and stakeholders need to urgently take action. The South African government and other governments in the world need to confront the impact of the COVID-19 pandemic in a positive way and address issues of equality and access to digital resources and educational resources in general. Nonetheless, some progress has been made by the South African government since the beginning of the COVID-19 pandemic. The South African government has partnered with several network 
providers (MTN, Cell C, Vodacom, etc.) to offer zero-rated applications and educational websites [26]; however, some learners could not access these resources due to challenges in network connectivity.

The study revealed that the COVID-19 pandemic has had an impact on the part that mathematics teachers play in developing and implementing a learning environment facilitated by technology. During ERT, teachers in the study learnt by trial and error the technology that would deliver content effectively in their context. In turn, teachers designed their teaching acting on the effectiveness of the technology and learners' responses. This finding seems to suggest that for technology to be adopted effectively, teachers must play a major part in decision making and must own the process of implementing the digital learning environment so that its adaptation in schools is long-lasting. Teachers must be made proponents in creating and executing the digital learning environment and must form communities of practice that focus on the use of technology so that they collaborate on its use and support one another.

Going forward, digital learning environments will be with us forever, such that professional development and teacher preparation programs in mathematics education must focus on the implementation of the digital learning environment. This is because teachers in contexts of disadvantage usually have limited experience in teaching mathematics with technology. Facilitators of professional development must do baseline studies to investigate teachers' needs on technology specific to their context. For professional development to be effective, teachers need to be listened to and their experiences during ERT due to the COVID-19 pandemic must be incorporated in their technology training.

Teachers were unsure of the true impact of the WhatsApp platform on mathematics learning, and this aspect needs to be investigated. There is no sufficient authoritative research on the impact of WhatsApp on the teaching and learning of mathematics in contexts of disadvantage; such research would help to fill this identified gap.

The study has limitations since it was located in one province during the COVID-19 lockdown and explored the teaching of mathematics in a context of historical disadvantage. This is a new research area; further systematic studies can be done in other contexts of disadvantage in several provinces of South Africa and around the world to provide further insights into the topic. The findings, implications and limitations from this study are valuable to all mathematics teachers and educators in South Africa and around the world since the COVID-19 pandemic has not ended. It is hoped that this study can inform mathematics teachers in contexts of disadvantage around the world on how to navigate the switch from face-to-face instruction to online environments in case the COVID-19 pandemic continues to impact the teaching and learning of mathematics.

Author Contributions: Conceptualization, B.C. and M.N.; methodology, B.C.; validation, B.C.; formal analysis, B.C., M.N. and E.S.; investigation, B.C.; resources, B.C.; data curation, B.C.; writing-original draft preparation, B.C.; writing—review and editing, B.C. and M.N.; visualization, B.C.; supervision, M.N. and E.S.; project administration, B.C. All authors have read and agreed to the published version of the manuscript.

Funding: This research received no external funding.

Institutional Review Board Statement: The study was conducted according to the guidelines of the Declaration of Helsinki and approved by the Ethics Committee of University of Johannesburg (protocol code 2-2019-017 and date of approval: 19 August 2019).

Informed Consent Statement: Informed consent was obtained from all respondents involved in the study.

Data Availability Statement: The data presented in this study are available on request from the corresponding author. The data are not publicly available due to privacy reasons.

Conflicts of Interest: The authors declare no conflict of interest. 


\section{References}

1. WHO. Coronavirus Disease (COVID-19) Pandemic. 2020. Available online: https://www.who.int/emergencies/diseases/novelcoronavirus-2019 (accessed on 14 January 2021).

2. UNESCO. Covid-19 Education Response. 2020. Available online: https://en.unesco.org/covid19/educationresponse/ globalcoalition (accessed on 3 January 2021).

3. Basilaia, G.; Kvavadze, D. Transition to online education in schools during a SARS-CoV-2 coronavirus (COVID-19) pandemic in Georgia. Pedagog. Res. 2020, 5, 1-9. [CrossRef]

4. Engelbrecht, J.; Borba, M.C.; Llinares, S.; Kaiser, G. Will 2020 be remembered as the year in which education was changed? ZDM Math. Educ. 2020, 52, 821-824. [CrossRef] [PubMed]

5. The World Bank Education Global Practice. Guidance Note: Remote Learning \& COVID-19; The World Bank: Washington, DC, USA, 2020.

6. Hodges, C.; Moore, S.; Lockee, B.; Trust, T.; Bond, A. The Difference between Emergency Remote Teaching and Online Learning. Educ. Rev. 2020. Available online: https://er.educause.edu/articles/2020/3/the-difference-between-emergency-remoteteaching-and-online-learning (accessed on 4 January 2021).

7. Hrastinski, S. Asynchronous and Synchronous E-Learning. Educ. Quart. 2008. Available online: https://er.educause.edu/ articles/2008/11/asynchronous-and-synchronouselearning (accessed on 14 January 2021).

8. Davies, L.; Bentrovato, D. Understanding Education's Role in Fragility: Synthesis of Four Situational Analyses of Education and Fragility: Afghanistan, Bosnia and Herzegovina, Cambodia, Liberia; IIEP Research Papers; UNESCO-IIEP: Paris, France, 2011.

9. Tauson, M.; Stannard, L. EdTech for Learning in Emergencies and Displaced Settings: A Rigorous Review and Narrative Synthesis; Save The Children: London, UK, 2018; Available online: https:/ / resourcecentre.savethechildren.net/node/13238//edtech-learning.pdf (accessed on 22 January 2020).

10. Aldon, G.; Cusi, A.; Schacht, F.; Swidan, O. Teaching Mathematics in a Context of Lockdown: A Study Focused on Teachers' Praxeologies. Educ. Sci. 2021, 11, 38. [CrossRef]

11. Drijvers, P. Moving Forward in the Midst of a Pandemic: International Lessons for Math Teachers. Presentation at the National Academies of Sciences, Engineering, and Medicine. 2020. Available online: https:/ /www.nationalacademies.org/event/07-09-20 20/math-distance-distance-mathematics-teaching-during-covid-19-lockdown (accessed on 28 November 2020).

12. Mailizar, A.; Almanthari, S.; Maulina, S. Bruce Secondary school mathematics teachers' views on E-learning implementation barriers during the COVID-19 pandemic: The case of Indonesia. Eurasia J. Math. Sci. Technol. Educ. 2020, 16, em1860. [CrossRef]

13. Naidoo, J. Postgraduate mathematics education students' experiences of using digital platforms for learning within the COVID-19 pandemic era. Pythagoras 2020, 41, a568. [CrossRef]

14. Czerniewicz, L.; Agherdien, N.; Badenhorst, J. A Wake-Up Call: Equity, Inequality and Covid-19 Emergency Remote Teaching and Learning. Postdigit. Sci. Educ. 2020, 2, 946-967. [CrossRef]

15. Black, S.; Spreen, C.; Vally, S. Education, COVID-19 and care: Social inequality and social relations of value in South Africa and the United States. South. Afr. Rev. Educ. 2020, 26, 40-61.

16. Statistics South Africa. Inequality Trends in South Africa: A Multidimensional Diagnostic of Inequality; Statistics South Africa: Pretoria, South Africa, 2019.

17. Bell, L. Theoretical foundations for social justice education. In Teaching for Diversity and Social Justice: A Sourcebook; Adams, M., Griffin, P., Bell, L., Eds.; Routledge: New York, NY, USA, 1997; pp. 3-26.

18. Van der Berg, S.; Spaull, N. Counting the Cost: COVID-19 School Closures in South Africa \& its Impacts on Children. Research on Socioeconomic Policy (RESEP). Stellenbosch: Stellenbosch University. 2020. Available online: https:/ / resep.sun.ac.za/wp-content/uploads/2020/06/Van-der-Berg-Spaull-2020-Counting-the-Cost-COVID-19-Childrenand-Schooling-15-June-2020-1.pdf (accessed on 14 January 2021).

19. McMillan, J.H.; Schumacher, S. Research in Education: Evidence-Based Inquiry, 7th ed.; Pearson: Harlow, UK, 2014.

20. Babbie, E. The Basics of Social Research, 7th ed.; CenGage Learning: Boston, MA, USA, 2017.

21. Ruben, A.; Babbie, E. Essential Research Methods for Social Work, 2nd ed.; Cole Engage Learning: Brooks, CA, USA, 2010.

22. Saldana, J. The Coding Manual for Qualitative Researchers, 3rd ed.; Sage: London, UK, 2016.

23. Creswell, J.W. Qualitative Inquiry and Research Method: Choosing Among Five Approaches, 4th ed.; Sage: Thousand Oaks, CA, USA, 2013.

24. Department of Basic Education. Basic Education and SABC launch Coronavirus COVID-19 TV and Radio Curriculum Support Programmes for Learners. 2020. Available online: https://gov.za/speeches/basic-education-andsabclaunchcoronavirus-covid19 tv-and-radio-curriculum-support (accessed on 11 January 2020).

25. Taylor, N. Education Researchers Respond to the COVID-19 Pandemic. Theme 1: Education at Home. 2020. Available online: https:/ / www.jet.org.za/resources/theme-1-overview-report-final.pdf (accessed on 10 January 2021).

26. Duncan-Williams, K. South Africa's Digital Divide Detrimental to the Youth. Mail and Guardian. 2020. Available online: https:/ / mg.co.za/article/2020-04-19-south-africas-digital-divide-detrimental-to-the-youth/ (accessed on 28 December 2020).

27. Owusu-Fordjour, C.; Koomson, C.K.; Hanson, D. The impact of Covid-19 on learning-the perspective of the Ghanaian student. Eur. J. Educ. Stud. 2020, 7, 88-101.

28. Guterres, A. Protect Our Children, United Nations. 2020. Available online: https://www.un.org/en/un-coronaviruscommunications-team/protect-our-children (accessed on 23 December 2020). 
29. Wright, L. How Pandemics Wreak Havoc-And Open Minds. The New Yorker. 2020. Available online: https://www.newyorker. com/magazine/2020/07/20/how-pandemics-wreak-havoc-and-open-minds (accessed on 13 December 2020).

30. Olivier, W. Education Post-COVID-19: Customised Blended Learning Is Urgently Needed. 2020. Available online: https: / / news.mandela.ac.zaNews/Education-post-COVID-19-customised-blended-learning (accessed on 14 January 2021). 